\title{
Price-cap regulation of airports: single-till
}

\author{
versus dual-till
}

Achim I. Czerny *

Berlin, 15th March 2005

\begin{abstract}
This paper takes up the debate whether price-cap regulation of airports should take the form of single-till or dual-till regulation. The contribution is to model single- and dual-till regulation, evaluate their welfare implications, and compare them to Ramsey charges. We show that single-till regulation dominates dual-till regulation at non-congested airports with regard to welfare maximization. However, none of them provides an airport with incentives to implement Ramsey charges. A Ramsey optimal price-cap regulation, which achieves this goal, is also presented.
\end{abstract}

JEL classification numbers: L51, L93, D42.

Keywords: Price-cap, airports, single-till, dual-till.

*Berlin University of Technology, Workgroup for Infrastructure Policy (WIP), aic@wip.tuberlin.de. Thanks to Kay Mitusch, Pio Baake, and Sascha Lukac for very helpful comments. 


\section{Introduction}

Until recently most airports were owned and managed by public authorities. Nonetheless, a growing number of airports in Europe as well as Australia and New Zealand became fully or partially privatized during the last twenty years. Furthermore, many airports in South-America, Africa, and Asia are under review for being privatized [11]. Airport privatization is almost always accompanied by some form of price regulation. This is basically due to the fact that airports are supposed to exhibit market power. However, Starkie claims that there would be a lack of incentives for airports to exploit it [12]. His conclusion is based on demand complementarities between aeronautical and commercial airport activities in combination with location rents. Aeronautical activities of the airport include the provision of take-off, landing, gangway, and parking capacity for aircraft and passengers. Commercial activities include, e.g., retailing and car parking. Roughly outlined, Starkie argues that increased airport charges do not only reduce the demand for flights, but also the demand for commercial services. This in turn reduces location rents and therefore the returns to the tenant, i.e., the airport itself. Following this reasoning the airport might not want to raise aeronautical charges so that airport regulation might be unnecessary.

In reality there is no fully liberalized airport market in the world, and airport policy makers are basically considering modifications of the present regulatory regimes. An example, on which we will focus in this paper, is the current debate about the single-till and dual-till approach to regulation. It centers around the issue mentioned above, namely, how regulation of aeronautical services should deal with airports' revenues from commercial services. Note that regulating charges on commercial services is not an issue; both approaches are only con- 
cerned with price-cap regulation of charges for aeronautical services. The key difference between single-till and dual-till regulation is that with single-till the price-cap is set in anticipation of the revenues from aeronautical and commercial services. Hence, under single-till regulation commercial revenues cover a portion of the airport's overall fixed costs, so that the single-till price-cap for aeronautical services is reduced accordingly. The dual-till approach, in contrast, tries to separate out the two airport business branches, particularly by attributing specified portions of airports' costs to aeronautical and commercial branches. Then, in order to guarantee that airport's aeronautical costs are completely covered by revenues from aeronautical activities, the dual-till price-cap for aeronautical charges is raised accordingly. Recently, in Australia, the United Kingdom, and Germany the question came up whether price-cap regulation could be improved by switching from single-till to dual-till regulation [3], [4], [10], [5].

Beesley was one of the first economists to attack single-till regulation [1]. He claims that regulation should concentrate on activities which are characterized by a natural monopoly, and therefore not be affected by the commercial activities. On the other hand, he doubts that it is possible to isolate the aeronautical activities from other airport activities. For this reason he generally rejects the application of a price-cap regulation mechanism to airports. Starkie, in contrast, is in favor of dual-till price-cap regulation [12]. He argues that, for non-congested airports, commercial airport activities should not be regulated because they could provide the airport with an incentive to reduce aeronautical charges. For congested airports, on the other hand, a dual-till regime would lead to higher aeronautical charges, which would have positive effects on the allocation of scarce slot capacity and on investment incentives. The reasoning 
is in line with the argument by Starkie and Yarrow [13]. Similar results are presented by Oum, Zhang, and Zhang [11] who provide empirical evidence that dual-till price-cap regulation improves economic efficiency in terms of total factor productivity for large, busy airports compared to the single-till approach. Somewhat different are the conclusions of Crew and Kleindorfer [6], and Lu and Pagliari [9]. They claim that for non-congested airports the use of a single-till system is beneficial. The former emphasize that single-till regulation is conducive to implement a Ramsey-like structure of charges, while the latter point out that it reduces aeronautical charges and, therefore, improves capacity utilization. However, for a congested airport Lu and Pagliari argue (in line with Starkie) in favor of dual-till regulation because then they expect the higher aeronautical charges to improve allocation.

The objective of this paper is to analyze the behavior of airports, and to contribute to the debate whether the single- or dual-till price-cap regulation is more appropriate. While the existing literature focuses on the effect of aeronautical charges on commercial airport activities, our model also takes into account the effects of commercial charges on the demand for aeronautical services. We model a two-stage regulation game in which we explicitly consider the regulators expectations on airport behavior and their impact on the single- or dual-till price-cap, respectively. In view of the literature mentioned above it should be pointed out that we confine attention to the case of a non-congested airport. It turns out that due to the specific complementarity of demands for aeronautical and commercial services a monopolistic airport would raise aeronautical charges rather than reduce them. In line with Crew and Kleindorfer and Lu and Pagliari it is also shown that single-till regulation dominates dual-till regulation at non- 
congested airports. This result is based on the fact that the single-till system implements an optimal regulation of aeronautical charges. However, neither the dual-till nor the single-till approach is able to implement Ramsey charges. The specific complementarity of demands requires the Ramsey charges for aeronautical services to be higher than those for commercial services. But this cannot be implemented by a regulation of aeronautical charges alone. We finally show that it is possible to implement Ramsey charges by use of a weighted-average price-cap regulation scheme.

The next section presents the model. The behavior of an unregulated monopolistic airport is considered in section 3. Section 4 analyzes Ramsey charges. The evaluation of single-till and dual-till price-cap regulation schemes follows in section 5. In section 6 an analysis of a Ramsey optimal price-cap regulation is provided. The paper closes with some concluding remarks in section 7 .

\section{Model}

The airport considered is a multi product monopolist which provides aeronautical and commercial services. We assume that the airport possesses market power in both markets, which is in line with several models used by other authors [6], [11], [14]. Moreover, we assume that there is no congestion, i.e. there is excess capacity for both aeronautical and commercial services.

Costs are described as follows. The airport incurs fixed costs of $F \geq 0$. For simplicity all variable airport costs are supposed to be zero (which fits to the assumption of excess capacity). Furthermore, airlines and commercial service providers are assumed to be in perfect competition and to have constant 
marginal costs. Then we can express consumers' willingness to pay and retail charges as net of the constant marginal costs. It follows that the airport charges for aeronautical and commercial services are identical to the (net) retail charges for consumers.

Turning to the demand side, we account for the fact that demands for the two airport services are heavily interdependent, although the types of services are quite different. The interdependency arises from the fact that the amount of passengers basically determines the demand for commercial airport services. We decide to model this interrelation explicitly.

There is a set of individuals denoted by $Q$ with mass one. Everyone flies at most once and buys at most one unit of a commercial good. Letting $p_{1} \geq 0$ denote the charge for a flight and $p_{2} \geq 0$ the charge for a commercial good, the consumer surplus of an individual $q \in Q$ who flies and buys is

$$
V_{1}(q)+V_{2}(q)-\left(p_{1}+p_{2}\right)
$$

where $V_{1}(q)$ is the willingness to pay for a flight and $V_{2}(q)$ that for a commercial good. It is assumed that both $V_{1}(q)$ and $V_{2}(q)$ are uniformly and independently distributed over the unit interval, i.e. $V_{1}(q), V_{2}(q) \in[0,1]$. Hence, in $V_{1}-V_{2}$-space, all individuals are uniformly and independently distributed over the unit square, as shown in figure 1. However, to take account for demand complementarity between aeronautical and commercial airport activities it is assumed that only passengers, i.e. individuals who decide to fly, can buy commercial services. Passengers make use of commercial services if $V_{2}(q)-p_{2} \geq$ 0. Individuals fly if they get a positive rent from flying and buying, i.e. if $V_{1}(q)-p_{1}+\max \left\{0, V_{2}(q)-p_{2}\right\} \geq 0$ is satisfied. From these conditions the demands for the two goods can be derived, as is now explained. 


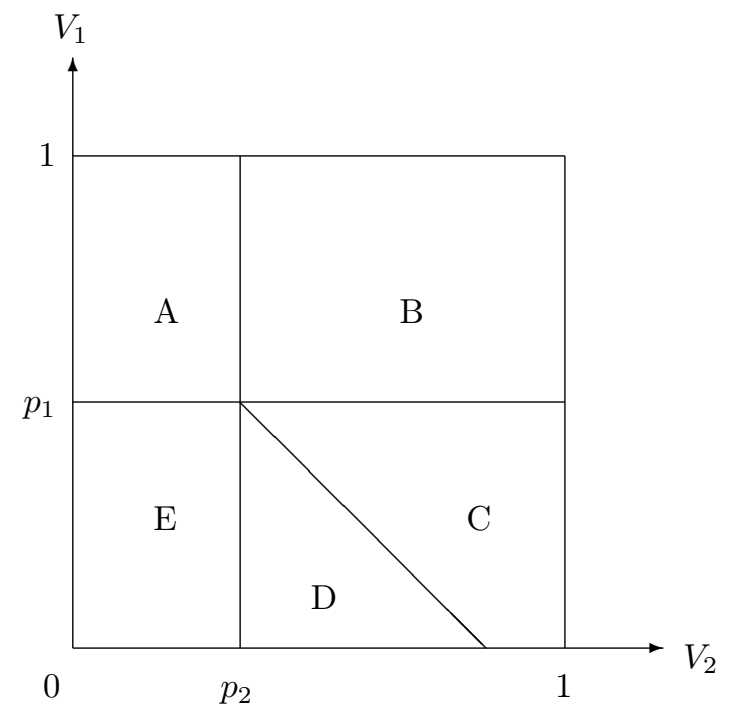

Figure 1: Passenger and consumer demand for given prices $p_{1}$ and $p_{2}$. The demand for flights, $D_{1}$, equals area $\mathrm{A}+\mathrm{B}+\mathrm{C}$. The demand for commercial services, $D_{2}$, equals the area $\mathrm{B}+\mathrm{C}$.

For given charges $p_{1}$ and $p_{2}$, the passenger demand $D_{1}$ and the demand for commercial airport services $D_{2}$ are illustrated in figure 1 . We show that

$$
D_{1}=\mathrm{A}+\mathrm{B}+\mathrm{C} .
$$

For all individuals in the areas A and B the utility of a flight is at least as high as $p_{1}$, hence, these individuals decide to fly. Note that individuals located in area $\mathrm{C}$ also buy a flight although $V_{1}(q) \leq p_{1}$. This is so because $p_{1}-V_{1}(q) \leq V_{2}(q)-p_{2}$ and, hence, the negative rent from flying is compensated by the positive rent generated from consumption of commercial services. Only individuals located in the areas $\mathrm{D}$ and $\mathrm{E}$ do not buy a flight, since $p_{1}>V_{1}(q)$ holds, and the rent 
generated by consumption is too small to compensate for the disutility resulting from flying. For $p_{1}+p_{2} \leq 1$ one calculates:

$$
\begin{aligned}
D_{1}\left(p_{1}, p_{2}\right) & =1-\int_{0}^{p_{2}} p_{1} d V_{2}-\int_{p_{2}}^{p_{1}+p_{2}} p_{1}+p_{2}-V_{2} d V_{2} \\
& =1-p_{1} p_{2}-\frac{p_{1}^{2}}{2} .
\end{aligned}
$$

Demand for commercial services is

$$
D_{2}=\mathrm{B}+\mathrm{C} .
$$

For individuals located in the areas $\mathrm{A}$ and $\mathrm{E}$ the utility for consumption is smaller than $p_{2}$, hence, they will not buy commercial services. Individuals located in area D do not consume aeronautical services simply because they are not at the airport (they do not fly). For $p_{1}+p_{2} \leq 1$ :

$$
\begin{aligned}
D_{2}\left(p_{1}, p_{2}\right) & =1-\int_{0}^{p_{2}} 1 d V_{2}-\int_{p_{2}}^{p_{1}+p_{2}} p_{1}+p_{2}-V_{2} d V_{2} \\
& =1-p_{2}-\frac{p_{1}^{2}}{2} .
\end{aligned}
$$

Since all variable costs are assumed to be zero, the welfare $W$ generated from flying and consuming is simply the sum of all actual buyers' willingness to pay for the two services. As we will now explain, it equals

$$
W:=1-\int_{\mathrm{E} \cup \mathrm{D}} V_{1} d V_{1} d V_{2}-\int_{\mathrm{A} \cup \mathrm{E} \cup \mathrm{D}} V_{2} d V_{1} d V_{2}
$$

With $p_{1}=p_{2}=0$ welfare is at its maximum (of 1 ), and the areas E, D, A are zero. The welfare loss caused by raising charges is given by the double integrals on the right hand side of equation (3). For $p_{1}+p_{2} \leq 1:^{1}$

\footnotetext{
${ }^{1}$ For $p_{1}+p_{2}>1$ and $p_{1}, p_{2} \leq 1$ it holds: $D_{1}=\frac{1}{2}\left(3-2 p_{1}-2 p_{2}+p_{2}{ }^{2}\right), D_{2}=$ $\frac{1}{2}\left(-1+p_{2}\right)\left(-3+2 p_{1}+p_{2}\right)$, and $W=\frac{1}{6}\left(7-3 p_{1}{ }^{2}+6 p_{1}\left(-1+p_{2}\right) p_{2}-6 p_{2}{ }^{2}+2 p_{2}{ }^{3}\right)$.
} 


$$
\begin{aligned}
W\left(p_{1}, p_{2}\right)= & 1-\int_{0}^{p_{2} p_{1}} \int_{0}^{p_{1}} V_{1} d V_{1} d V_{2}-\int_{p_{2}}^{p_{1}+p_{2}} \int_{0}^{p_{1}+p_{2}-V_{1}} V_{1} d V_{1} d V_{2} \\
& -\int_{0}^{p_{2}} \int_{0}^{p_{2}} V_{2} d V_{2} d V_{1}-\int_{p_{1}}^{1} \int_{0}^{2} V_{2} d V_{2} d V_{1} \\
= & 1-\frac{p_{1}^{3}}{3}-p_{1}^{2} p_{2}-\frac{p_{2}^{2}}{2} .
\end{aligned}
$$

\section{An unregulated monopolistic airport}

Which effect does the integration of commercial activities into the airports' optimization problem have on aeronautical charges? For an illustration, assume that $p_{2}=1$. Then nobody will demand airport commercial services, since $V_{2}(q) \leq 1$ for every individual $q$, and it follows that aeronautical demand is $D_{1}=1-p_{1}$. Since marginal costs are zero, profit from aeronautical activities is then maximized by $p_{1}=0.5$. Now assume to the contrary that $p_{1}=0$. Then everyone buys a flight, the demand for commercial services is $D_{2}=1-p_{2}$, and the profit maximizing charge for commercial services is $p_{2}=0.5$. Now consider an airport which optimizes profits by simultaneous choice of aeronautical and commercial charges. Since the two services are complementary we would expect one price to be reduced below 0.5 , and the other raised above 0.5 . Which charge will be raised and which one reduced? The airports' maximization problem is given by:

$$
\max _{0 \leq p_{1}, p_{2}} \Pi\left(p_{1}, p_{2}\right)
$$

with $\Pi\left(p_{1}, p_{2}\right):=p_{1} D_{1}\left(p_{1}, p_{2}\right)+p_{2} D_{2}\left(p_{1}, p_{2}\right)-F$. For $p_{1}+p_{2} \leq 1$ equations (1) and (2) imply

$$
\Pi\left(p_{1}, p_{2}\right)=p_{1}-\frac{p_{1}^{3}}{2}+p_{2}-\frac{3 p_{1}^{2} p_{2}}{2}-p_{2}^{2}-F .
$$


The solution for (5) is given by $\left(p_{1}^{M}, p_{2}^{M}\right)=(2 / 3,1 / 6)$ where the superscript $M$ is used to denote monopoly charges. It implies $D_{1}\left(p_{1}^{M}, p_{2}^{M}\right)=2 / 3, D_{2}\left(p_{1}^{M}, p_{2}^{M}\right)=$ $11 / 18, W\left(p_{1}^{M}, p_{2}^{M}\right) \approx 0.81$, and $\Pi\left(p_{1}^{M}, p_{2}^{M}\right) \approx 0.55-F .^{2}$ This shows that simultaneous profit maximization in fact raises aeronautical charges above 0.5 and reduces charges for commercial services below 0.5. This is contrary to the hypothesis mentioned in the literature that an unregulated airport would reduce aeronautical charges in order to raise the profitability of commercial activities [12].

The intuition for this result is to be seen in the complementary nature of demand for the two goods. Since only passengers can buy commercial services, the demand for the latter is a subset of the demand for flights, i.e. $D_{1}>$ $D_{2}$ (except for $p_{2}=0$ where $D_{1}=D_{2}$ ). Hence, raising aeronautical charges increases revenues by a larger amount than raising commercial charges.

Because all real airports are regulated in some way it is difficult to verify whether $p_{1}^{M}>p_{2}^{M}$ holds empirically. However, current experience with Australian airports shows that airports indeed tend to raise aeronautical charges if they are allowed to do so. After replacing price-cap regulation of Australian airports by a system of price-monitoring in 2002, some of them have even doubled aeronautical charges [7]. This shows that airports have a strong incentive to raise aeronautical charges in spite the fact that this might have negative effects on revenues from commercial activities. Another observation from the airline industry also provides some evidence for the above result. Before the airline industry was liberalized many airlines were in fact regional monopolists. At that time they passed commercial services to passengers for free (e.g. food,

\footnotetext{
${ }^{2}$ One checks that the monopolist will never choose a combination with $p_{1}+p_{2}>1$.
} 
beverages, and newspapers), presumably in an attempt to make flights more attractive.

\section{Ramsey charges}

The monopoly solution analyzed in the last section leads to a welfare loss (of approximately 0.19 ) compared to the welfare maximum (of 1 ). On the other hand, welfare maximizing charges, $p_{1}=p_{2}=0$, do not cover the airport's fixed costs. Denote by $R\left(p_{1}, p_{2}\right):=p_{1} D_{1}\left(p_{1}, p_{2}\right)+p_{2} D_{2}\left(p_{1}, p_{2}\right)$ the revenue of the airport. Assume that $F \leq R\left(p_{1}^{M}, p_{2}^{M}\right)$ so that the monopoly profit is non-negative. Then we can consider Ramsey charges, denoted by $\left(p_{1}^{R}, p_{2}^{R}\right)$, which are a compromise between welfare maximization and profitability. The corresponding optimization problem is

$$
\max _{0 \leq p_{1}, p_{2}} W\left(p_{1}, p_{2}\right) \text { s.t. } \Pi\left(p_{1}, p_{2}\right) \geq 0 .
$$

The solution for $(6)$ is plotted in figure 2 as a function of $F$. Observe that $p_{2}^{R}=0$ holds if fixed costs are below a critical amount $\hat{F} \approx 0.485$. Moreover it holds:

Proposition 1 Ramsey charges satisfy $p_{1}^{R}>p_{2}^{R}$ for all $F>0$.

Proof For $F \in(0, \hat{F})$ Ramsey charges for the commercial services are $p_{2}^{R}=0$.

Consequently, $p_{1}^{R}>0=p_{2}^{R}$ must hold to cover fixed costs.

For $F \in\left[\hat{F}, R\left(p_{1}^{M}, p_{2}^{M}\right)\right]$ the first order conditions for (6) imply

$$
p_{1}^{R}=2-p_{2}^{R}-\sqrt{2-4 p_{2}^{R}+\left(p_{2}^{R}\right)^{2}},
$$

from which it follows that $p_{1}^{R}>p_{2}^{R}$. 


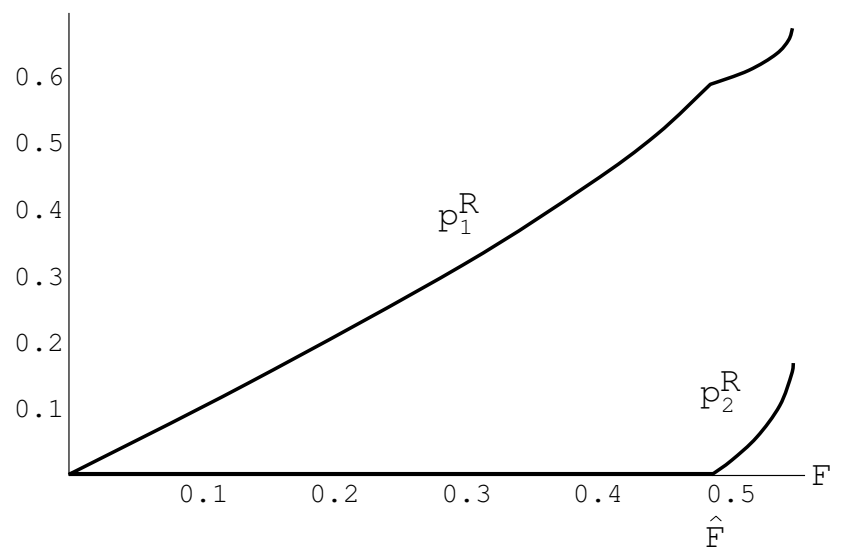

Figure 2: Ramsey charges. $p_{1}^{R}$ : aeronautical Ramsey charges. $p_{2}^{R}$ : commercial Ramsey charges.

Similar to the monopoly case, aeronautical Ramsey charges are higher than commercial Ramsey charges. The intuition is similar, too. Starting from $p_{1}=$ $p_{2}=0$, raising charges for aeronautical services generates more revenues than raising commercial charges by the same amount.

It has been pointed out that cross-subsidization between commercial and aeronautical airport operations can be welfare enhancing [14]. Note, however, our result shows that the desirability of cross-subsidization strongly depends on the amount of fixed costs. If $F \leq \hat{F}$ commercial prices should not be raised above marginal costs. Only for relatively high fixed costs $(F>\hat{F})$ should commercial charges be used to cover a portion of fixed airport costs. 


\section{Single-till versus dual-till}

We now address the comparison between single-till and dual-till price-cap regulation and their relation to Ramsey charges. Under both approaches only aeronautical charges are directly regulated by a price-cap [3], [5]. Hence, the regulator defines a price cap $\bar{p}^{a} \geq 0$ with $a \in\{s, d\}$, which restricts aeronautical charges to satisfy $p_{1} \leq \bar{p}^{a}$. The indices denote the price-cap under single-till $(a=s)$ or dual-till regulation $(a=d)$.

Single-till regulation takes profits from aeronautical as well as commercial activities into account when determining the price-cap. The way of calculating a single-till price-cap is ideally given by

$$
\bar{p}^{s}=\max \left\{0, \frac{F-p_{2} D_{2}\left(p_{1}, p_{2}\right)}{D_{1}\left(p_{1}, p_{2}\right)}\right\} .
$$

Thus, the single-till price-cap is given by the maximum of zero and the average fixed costs per passenger minus the average profits resulting from commercial activities per passenger. Rearranging (8) shows that a positive single-till pricecap $\left(\bar{p}^{s}>0\right)$ is equivalent to a zero profit condition (i.e. $R\left(p_{1}, p_{2}\right)=F$ or $\left.\Pi\left(p_{1}, p_{2}\right)=0\right)$. A dual-till price-cap is ideally given by

$$
\bar{p}^{d}=\frac{\alpha F}{D_{1}\left(p_{1}, p_{2}\right)}
$$

where $\alpha \in[0,1]$ is the share of the fixed costs which are attributable to aeronautical services. ${ }^{3}$ The dual-till price-cap is given by the average fixed costs attributable to aeronautical activities per passenger. Note, if the commercial activities are profitable, i.e. $p_{2} D_{2}>(1-\alpha) F$, then it follows that $\bar{p}^{s}<\bar{p}^{d}$.

\footnotetext{
${ }^{3} \mathrm{We}$ assume that fixed costs are perfectly attributable to the different airport activities, although we agree with other authors that this might be difficult [1]. However, this is a necessary pre-condition for a dual-till approach to be workable.
} 
Our analysis of single- and dual-till regulation will be based on the assumptions that the above formulas are to be taken seriously, and that the regulator has rational expectations of the airport's reaction to a price-cap. Formally, this amounts to a regulation game with two stages under perfect information. In the first stage the regulator determines the price-cap $\bar{p}$, given by either (8) or (9), and in the second stage the airport chooses charges $\left(p_{1}, p_{2}\right)$ so as to maximize profit subject to the price-cap and the non-negativity constraints.

Solving backwards, we obtain the airport's optimal strategy, or pair of reaction functions:

$$
\left(p_{1}^{r}(\bar{p}), p_{2}^{r}(\bar{p})\right):=\arg \max _{0 \leq p_{1}, p_{2}} \Pi\left(p_{1}, p_{2}\right) \quad \text { s.t. } p_{1} \leq \bar{p}
$$

One shows that there is indeed a unique solution to the airport's problem. The price-cap is binding, i.e. $p_{1}^{r}=\bar{p}$, if and only if $\bar{p} \leq 2 / 3$. The non-negativity constraint on $p_{2}$ is not binding, so that $p_{2}^{r}$ is given by the first-order condition $\partial \Pi\left(p_{1}^{r}, p_{2}^{r}\right) / \partial p_{2}=0$.

In the first stage of the regulation game the airport sets $\bar{p}$. For single-till regulation, $\bar{p}^{s}$ is the maximum of zero and the solution to

$$
\bar{p}=\frac{F-p_{2}^{r}(\bar{p}) D_{2}\left(p_{1}^{r}(\bar{p}), p_{2}^{r}(\bar{p})\right)}{D_{1}\left(p_{1}^{r}(\bar{p}), p_{2}^{r}(\bar{p})\right)} .
$$

For dual-till regulation, $\bar{p}^{d}$ is the solution to

$$
\bar{p}=\frac{\alpha F}{D_{1}\left(p_{1}^{r}(\bar{p}), p_{2}^{r}(\bar{p})\right)} .
$$

Note that the solutions for (10) and (11) are unique and that they constitute the unique subgame perfect Nash-equilibrium of the regulation game.

Under single-till regulation the Nash-equilibrium depends on $F$ only, while under dual-till regulation it depends on $F$ and $\alpha$. Figures 3 and 4 show the 


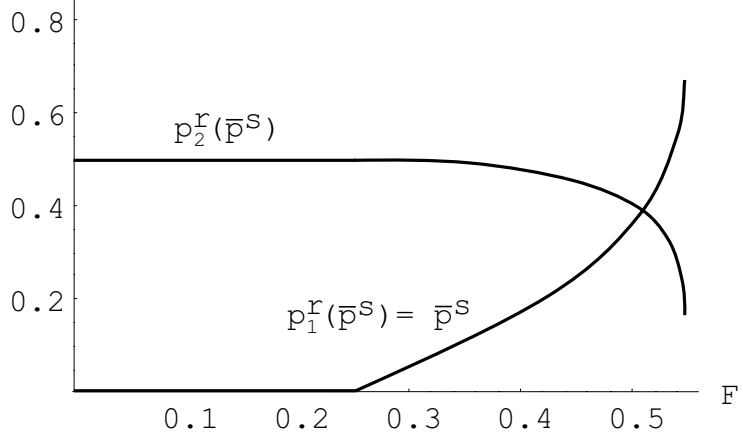

Figure 3: Charges implied by subgame perfect Nash-equilibria under single-till regulation for varying amounts of $F$.

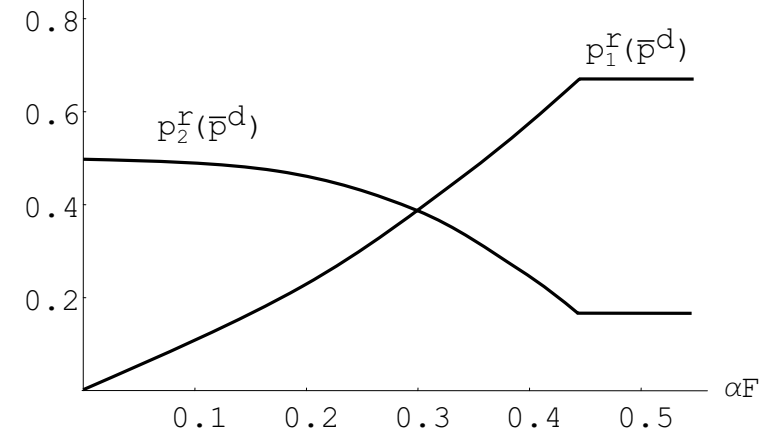

Figure 4: Charges implied by subgame perfect Nash-equilibria under dual-till regulation for varying amounts of $\alpha F$. 
charges implied by the Nash-equilibria with varying amounts of $F$, respectively $\alpha F$. Under dual-till regulation the airport is allowed to charge monopoly prices if $\alpha F \gtrsim 0.44$ holds. In contrast, under the single-till approach monopoly prices are only allowed for the boundary case $F=R\left(p_{1}^{M}, p_{2}^{M}\right)$. However, which regulation scheme should be preferred? The following proposition and corollary show that single-till regulation (weakly) dominates dual-till regulation from a welfare perspective.

Proposition 2 The welfare maximizing price-cap for the aeronautical charges, subject to a zero-profit condition, is equivalent to single-till regulation.

Proof The welfare maximizing regulation of airport charges is the solution to

$$
\max _{0 \leq \bar{p}} W\left(p_{1}, p_{2}\right) \quad \text { s.t. } \Pi\left(p_{1}, p_{2}\right) \geq 0 \text { and }\left(p_{1}, p_{2}\right)=\left(p_{1}^{r}(\bar{p}), p_{2}^{r}(\bar{p})\right) \text {. }
$$

At the solution it holds either $\Pi\left(p_{1}, p_{2}\right)=0$ or $\bar{p}=0$. Hence, the solution must be equivalent to the single-till price-cap, since $\bar{p}^{s}>0$ is equivalent to a zero-profit condition as was shown above.

Corollary 1 Single-till regulation strictly dominates dual-till regulation if $F \in$ $\left(0, R\left(p_{1}^{M}, p_{2}^{M}\right)\right)$ and $(1-\alpha) F \neq p_{2}^{s} D_{2}\left(p_{1}^{s}, p_{2}^{s}\right)$.

Proof The conditions imply that $\bar{p}^{d} \neq \bar{p}^{s}$.

To provide an intuition for proposition 2 , one can calculate that $\partial W\left(\bar{p}, p_{2}(\bar{p})\right) / \partial \bar{p} \leq$ 0 for $\bar{p} \leq 2 / 3$. Thus, in order to maximize welfare the regulator should try to implement the lowest possible price-cap for aeronautical charges, i.e., the one for which either $\Pi=0$ or $\bar{p}=0$. However, this is the one also implemented by single-till regulation. A particular advantage of single-till follows from the fact 
that it allows complete control of the overall profits of the airport, which is not the case with dual-till regulation.

Note, however, that even the single-till approach cannot implement Ramsey charges, since it regulates only aeronautical charges. That is, we have $\left(p_{1}^{r}\left(\bar{p}^{s}\right), p_{2}^{r}\left(\bar{p}^{s}\right)\right) \neq\left(p_{1}^{R}, p_{2}^{R}\right)$ for all $F<R\left(p_{1}^{M}, p_{2}^{M}\right)$. For this reason, the following section proposes a price-cap regulation scheme which is capable to implement Ramsey charges.

\section{A Ramsey optimal price-cap regulation}

To implement Ramsey charges the aeronautical as well as commercial charges have to be integrated into the price-cap formula. Suppose that the average airport charges with weights $\left(w_{1}, w_{2}\right)$ are restricted by a cap $\bar{p}$ as follows:

$$
w_{1} p_{1}+w_{2} p_{2} \leq \bar{p}
$$

We show that a price-cap $\bar{p}$ and price-weights $\left(w_{1}, w_{2}\right)$ exist which guarantee that a profit maximizing airport will reproduce $\left(p_{1}^{R}, p_{2}^{R}\right)$.

Proposition 3 A price-cap of

$$
\bar{p}=\left\{\begin{array}{r}
F \quad \text { for } \quad F \geq \hat{F} \\
p_{1}^{R} \quad \text { for } \quad F<\hat{F}
\end{array}\right.
$$

in combination with price weights

$$
\left(w_{1}, w_{2}\right)=\left\{\begin{array}{rr}
\left(D_{1}\left(p_{1}^{R}, p_{2}^{R}\right), D_{2}\left(p_{1}^{R}, p_{2}^{R}\right)\right) & \text { for } \quad F \geq \hat{F} \\
(1,1) & \text { for } \quad F<\hat{F}
\end{array}\right.
$$

guarantees that the airport sets $\left(p_{1}, p_{2}\right)=\left(p_{1}^{R}, p_{2}^{R}\right)$. 
Proof Assume $F \geq \hat{F}$. Since $W=W-\Pi+\Pi$, the Lagrangean for the Ramsey problem (6) can be expressed as

$$
\mathscr{L}=W\left(p_{1}, p_{2}\right)-\Pi\left(p_{1}, p_{2}\right)+(1+\lambda) \Pi\left(p_{1}, p_{2}\right) .
$$

Since $W-\Pi$ is equivalent to an indirect utility function, rearranging the first order condition for (13), after inserting $\partial(W-\Pi) / \partial p_{j}=-D_{j}$ given by Roy's identity, produces the following characterization of Ramsey charges:

$$
-\frac{1}{D_{j}\left(p_{1}^{R}, p_{2}^{R}\right)} \sum_{i=1}^{2} p_{i}^{R} \frac{\partial D_{i}}{\partial p_{j}}=\frac{\lambda^{R}}{1+\lambda^{R}}
$$

Consider now the optimization problem of a monopolistic airport subject to constraint (12). The respective Lagrangean is

$$
\mathscr{L}=\Pi\left(p_{1}, p_{2}\right)+\mu\left(\bar{p}-w_{1} p_{1}-w_{2} p_{2}\right)
$$

Rearranging the first order condition for (15) generates

$$
-\frac{1}{w_{j}} \sum_{i=1}^{2} p_{i}^{*} \frac{\partial D_{i}}{\partial p_{j}}=1-\mu^{*}
$$

For $w_{j}=D_{j}\left(p_{1}^{R}, p_{2}^{R}\right)$ and $\bar{p}=F$ it follows $\mu^{*}=1 /\left(1+\lambda^{R}\right)$. Hence, the conditions (14) and (16) are equivalent and therefore $\left(p_{1}^{*}, p_{2}^{*}\right)=\left(p_{1}^{R}, p_{2}^{R}\right){ }^{4}$

For $F<\hat{F}$ the Ramsey price for commercial services $p_{2}^{R}=0$ reflects a boundary solution, and the former result does not hold. However, for $w_{1}=$ $w_{2}=1$ the first order conditions of (15) imply $p_{2}^{*}=0$. Moreover, with $\bar{p}=p_{1}^{R}$, the Ramsey solution will be reproduced for $F<\hat{F}$.

Why do price weights $w_{1}=w_{2}=1$ provide the airport with no incentives to set $p_{2}>0$ ? The intuition behind this result is, again, based on the complementarities between the demands for aeronautical and commercial services.

\footnotetext{
${ }^{4}$ The argument is similar to Laffont and Tirole [8].
} 
With equal price weights in the price-cap formula an increase of $p_{2}$ has to be compensated by an equiproportional decrease of $p_{1}$. This, however, would not be profitable.

\section{Conclusions}

Airport privatization has almost always been accompanied by some form of price-regulation. Our paper focuses on the current debate whether price-cap regulation of monopolistic airports should take the form of single-till or dual-till regulation.

In order to address this issue we modelled the market interdependency between aeronautical and commercial airport activities and its impact on charges for a non-congested airport. In particular, the demand for aeronautical and commercial services is highly complementary. We showed that this has an important implication: An unregulated monopolistic airport would tend to reduce charges for commercial services in order to raise the charges for flights.

Since first-best charges would imply losses for a non-congested airport we also considered Ramsey charges. As with monopolistic charges, it turned out that Ramsey charges for aeronautical services are higher than the respective charges for commercial services. Moreover, our analysis shows that any crosssubsidization of aeronautical services by profits generated from commercial activities is only welfare enhancing if fixed costs are fairly large.

Furthermore, we point out that at non-congested airports single-till regulation dominates dual-till regulation from a welfare point of view. This result is due to the fact that single-till regulation is equivalent to an optimal price-cap 
regulation for aeronautical charges. However, even the single-till approach does not provide the monopolist with incentives to implement Ramsey charges. For a broad range of fixed costs, the aeronautical charges implied by single-till and dual-till regulation are lower than the charges for commercial services. This strongly thwarts the idea of Ramsey charges. It is shown that Ramsey charges can be implemented by use of a weighted average price-cap regulation scheme on both charges.

What can we learn from this analysis for the case of a congested airport? The picture changes somewhat, but a single-till regulation might remain advantageous. In the case of congestion, optimal charges have to take the external congestion costs of an additional flight into account. ${ }^{5}$ This raises airports' revenues and reduces the deficit-problem or even guarantees excessive profits. Therefore, the first-best solution can still be undesired because airport revenues and profits might be very high. If this is the case, we learned that a singletill regulation is preferable because it can more effectively control the overall profits of the airport. On the other hand, compared to dual-till regulation, the application of single-till regulation cuts aeronautical charges and, thus, will raise excess demand. However, coordinating airport access by scheduled slots in combination with e.g. slot auctions or slot trading can reduce the resulting slot allocation problem.

\footnotetext{
${ }^{5}$ Brueckner shows that the surcharge should be reciprocally proportional to the market shares of airlines [2].
} 


\section{References}

[1] Michael E. Beesley. Airport regulation. In Michael E. Beesley, editor, Regulating Utilities: A New Era? Institute of Economic Affairs, London, 1999.

[2] Jan K. Brueckner. Airport congestion when carriers have market power. American Economic Review, 92(5):1357-1375, dec 2002.

[3] Civil Aviation Authority CAA, editor. The 'Single Till' and the 'Dual Till' Approach to the Price Regulation of Airports, Consultation Paper, London, $\operatorname{dec} 2000$

[4] Civil Aviation Authority. Economic Regulation of BAA London Airports, CAA Decisions, London, feb 2003.

[5] Productivity Commission. Price regulation of airport services. Inquiry Report 19, jan 2002.

[6] Michael Crew and Paul Kleindorfer. Regulation for privatized airports: Single-till versus multi-till pricing methodologies for sydney airport. 2001.

[7] Peter Forsyth. Replacing regulation: airport price monotoring in Australia. In P. Forsyth, D.W. Gillen, A. Knorr, O.G. Mayer, H.-M. Niemeier, and D. Starkie, editors, The Economic Regulation of Airports, Ashgate Studies in Aviation Economics and Management, pages 3-22. 2004.

[8] Jean-Jacques Laffont and Jean Tirole. Competition in Telecommunications. Munich Lectures in Economics. The MIT Press, 2000. 
[9] Ching-Chiyuan Lu and Roman I. Pagliari. Evaluating the potential impact of alternative airport pricing approaches on social welfare. Transportation Research Part E, (40):1-17, 2004.

[10] Hans-Martin Niemeier. Regulation of airports: the case of Hamburg airport - a view from the perspective of regional policy. Journal of Air Transport Management, 8(1):37-48, jan 2002.

[11] Tae Hoon Oum, Anming Zhang, and Yimin Zhang. Alternative forms of economic regulation at airports. Journal of Transport Economics and Policy, 38(2):217-246, mai 2004.

[12] David Starkie. Reforming UK airport regulation. Journal of Transport Economics and Policy, (35):119-135, 2001.

[13] David Starkie and George Yarrow. The single till approach to the price regulation of airports. 2000 .

[14] Anming Zhang and Yimin Zhang. Concession revenue and optimal airport pricing. Transportation Research E, (4):287-296, 1997. 